\title{
Fake News em tempos de COVID-19 e seu tratamento jurídico no ordenamento brasileiro
}

\author{
Fake News in times of COVID-19 and its legal treatment in Brazilian law \\ Fake News en tiempos de COVID-19 y su tratamiento legal en la legislación brasileña
}

Alexandre Magalhães de Mattos $^{1}$ (1) Ingrid Zuvanov Kahl Costa $^{1}$ (1) Mercedes Neto $^{2}$ (1)

Ricardo de Mattos Russo Rafael ${ }^{2}$ (1) Eloá Carneiro Carvalho ${ }^{3}$ (D)

Fernando Porto ${ }^{1}$ (D)

1. Universidade Federal do Estado do Rio de Janeiro, Escola de Enfermagem Alfredo Pinto. Rio de Janeiro, RJ, Brasil.

2. Universidade do Estado do Rio de Janeiro, Faculdade de Enfermagem, Programa de Pósgraduação em Enfermagem. Rio de Janeiro, RJ, Brasil.

3. Universidade do Estado do Rio de Janeiro, Faculdade de Enfermagem. Rio de Janeiro, RJ, Brasil.
Autor correspondente:

Mercedes Neto.

E-mail: mercedesneto.uerj@gmail.com

Recebimento em 17/12/2020.

Aprovado em 17/03/2021.

DOI:https://doi.org/10.1590/2177-9465-EAN-2020-0521

\section{Resumo}

Objetivo: refletir sobre o tratamento jurídico dispensado aos casos das Fake News relacionados à COVID-19 no campo do Direito brasileiro. Método: estudo de reflexão tendo como referencial as consequências da aplicação do arcabouço jurídico brasileiro aos casos de Fake News sobre COVID-19. As fontes são oriundas de outro estudo com lacunas deixadas no sentido das aplicações pelo ordenamento jurídico. Para discussão, balizou-se o enquadramento das Fake News ao ordenamento jurídico. Resultados: são oriundos de estudo anterior que identificou e agrupou as Fake News encontradas no banco de dados do Ministério da Saúde por temas, a saber: discursos de autoridades na saúde, terapêutica, medidas de prevenção, prognósticos da doença e vacinação. Considerações finais e implicações para prática: foi possível depreender que a prática de compartilhamento de mensagens, imagens, áudios e/ou vídeos realizadas por diversos indivíduos nas redes sociais, sem a preocupação de se verificar se são verídicas, é um ato que pode ser configurado como crime.

Palavras-chave: Infecções por Coronavírus; Notícias; Crime; Legislação; Saúde.

\section{Abstract}

Objective: to reflect on the legal treatment given to the Fake News cases related to COVID-19 in the field of Brazilian law. Method Reflection study based on the consequences of applying the Brazilian legal framework to the Fake News cases on COVID-19. The sources come from another study with gaps left in the sense of applications by the legal system. For discussion, the framing of false news to the legal system was marked out. Results: They come from a previous study that identified and grouped as False News found in the Ministry of Health database by themes, a saber: speeches by health authorities, therapeutics, preventive measures, prognosis of the disease and vaccination. Final considerations and conclusion for practice: It was possible to conclude that the practice of sharing messages, images, audios and / or videos performed by several members of social networks, without the concern of verifying whether they are true, is an act that can be configured as a crime.

Keywords: Coronavirus Infections; News; Crime; Legislation; Health.

\section{Resumen}

Objetivo: reflexionar sobre el tratamiento legal dado a los casos de Fake News relacionados con COVID-19 en el ámbito del derecho brasileño. Método: Estudio de reflexión basado en las consecuencias de la aplicación del marco legal brasileño a los casos de Fake News sobre COVID-19. Las fuentes provienen de otro estudio con lagunas dejadas en el sentido de aplicaciones por parte del sistema legal. Para la discusión, se marcó el encuadre de noticias falsas al sistema judicial. Resultados: Provienen de un estudio previo que identificó y agruparon como Noticias Falsas encontradas en la base de datos del Ministerio de Salud por temas, un sable: discursos de las autoridades sanitarias, terapéuticas, medidas preventivas, pronóstico de la enfermedad y vacunación. Consideraciones finales y conclusión para la práctica: Se pudo concluir que la práctica de compartir mensajes, imágenes, audios y / o videos realizada por varios miembros de las redes sociales, sin la preocupación de verificar si son verdaderos, es un acto que puede ser configurado como delito.

Palabra clave: Infecciones por Coronavirus; Crimen; Noticias; Legislación; Salud. 


\section{INTRODUÇÃO}

As Notícias Falsas, conhecidas internacionalmente como Fake News, circulam em todas as mídias sociais e a cada dia surge uma nova e as pessoas as recebem quase em tempo e a hora de sua criação, um fenômeno histórico que ocorre desde o Império Romano, agravado na atualidade pela internet.

O Ministério da Saúde, em 2018, criou um sítio eletrônico tendo por objetivo combater as Fake News e propor esclarecimentos dos fatos com base nas evidências científicas e suas fontes. $A$ necessidade para a providência ocorreu em virtude de mensagens veiculadas em aplicativos da internet e similares que propagavam informações equivocadas para a população a respeito da febre amarela, gripe e sarampo ${ }^{1}$.

Nessa perspectiva, alguns pesquisadores ${ }^{2-4}$ se debruçaram sobre diversos aspectos no sentido de combaterem intelectualmente as Fake News. Nessa lógica, desenvolveram estudos que apontavam as pseudoinformações dos agravos à saúde com diálogo do presente com o passado e suas ocorrências e interferências no campo social, político e sanitário. Isto posto, confundi à população, mesclando imagens imateriais do passado, como se tivessem ocorridas no presente, fora do contexto, e assertivas sem as evidências científicas necessárias para tomarem condutas de cuidados, por exemplo.

Faz-se mister destacar que se entende por Fake News aquelas informações/notícias/postagens produzidas de forma inverossímil e sem averiguação, logo, pseudoinformações ${ }^{4,5}$.

A repercussão das Fake News nas redes sociais é rápida e, algumas vezes, por (in)conscientes elas passam a ser veiculadas como verdades. Isto implica que elas podem causar danos irreversíveis pela ausência de comprovação científica. Seguir nessa linha de pensamento, requer prudência na conduta a ser tomada, já que se corre o risco de tomadas de decisão equivocadas, e até criminosas.

Contudo, identificar as Fake News, combatê-las pelos meios de comunicação e vigiá-las no campo virtual são atitudes salutares. Entretanto, há de se pensar no campo do direito, ou seja, no uso dos dispositivos legais como ferramenta no combate à pseudoinformação.

$\mathrm{Na}$ atualidade, o mundo virtual, a internet ou ciberespaço configuram um novo ambiente tecnológico, potencializado em tempos pandêmicos, que permite diversas formas de expressão de ideias, informações e transações econômicas ${ }^{6}$.

No campo da informática, as infrações penais podem ser divididas em duas categorias. A primeira se refere aos atos dirigidos contra o sistema de informática, contra o computador e dados ou programas e; a segunda é aquela cometida por intermédio do sistema de informática, a saber, contra o patrimônio, a liberdade individual e a propriedade imaterial ${ }^{7}$.

Hodiernamente, o mundo encontra-se em meio à pandemia da COVID-19, assim denominada pela Organização Mundial de Saúde, em 11 de março de $2020^{4}$. Isto ocorreu após o aparecimento de um novo subtipo viral de Severe Acute Respiratory Syndrome Coronavirus (SARS-Cov), mais conhecido pela população como coronavírus, o qual foi identificado na China, classificado e denominado como SARS-Cov2.

Ressalta-se que os números de casos confirmados com infecções por coronavírus- COVID-19- no mundo, até a primeira semana de abril de 2020, foram de 1.210.956 tendo por óbitos 67.594 pessoas, o que representa a taxa de letalidade de $5,6 \%$. Delimitado, geograficamente, no Brasil os dados apontavam para 12.056 casos confirmados, 553 óbitos e taxa de letalidade de $4,6 \%^{8}$.

Assim sendo, no período de 29 de janeiro a 31 de março de 2020, 70 registros foram identificados no banco de dados do Ministério da Saúde, os quais foram classificados em 40 sobre terapêutica, 17 a respeito de medidas de prevenção, nove relacionados a prognósticos da doença e duas acerca de vacinação ${ }^{4}$. Essas notícias coletadas, pela delimitação temporal, trata-se de um exemplo de mecanismos criminosos, em meio ao início da pandemia de COVID-19, de ataque às condutas de assistência e prevenção de riscos que estavam sendo moduladas e aplicadas, o que reflete no campo da enfermagem sobre os cuidados a serem prestados.

Mediante o exposto, definiu-se como questão norteadora: como as Fake News podem ser enquadradas nos dispositivos legais do ordenamento jurídico brasileiro? Para tanto, estabeleceu-se como objetivo refletir sobre o tratamento jurídico dispensado aos casos das Fake News relacionados à COVID-19 no campo do direito brasileiro.

A apresentação das reflexões foi delineada em dois eixos temáticos, a saber: a aplicação das técnicas de argumentação na construção das Fake News e à luz do ordenamento jurídico brasileiro. Salienta-se que esses eixos temáticos despontaram da literatura pesquisada e da experiência vividas pelos autores em relação às consequências das Fake News no combate à pandemia da COVID-19.

O estudo se justifica a partir da leitura do artigo Fake News no cenário da pandemia de COVID-19, ${ }^{4}$ pois os dados encontrados chamaram a atenção pelo quantitativo de Fake News registrado pelo Ministério da Saúde. Logo, acredita-se que o presente estudo é relevante devido ao risco à saúde da população ocasionado pela disseminação de Fake News, principalmente em meio à pandemia causada pelas infecções por coronavírus, a COVID-19. Além de possibilitar uma reflexão sobre as possíveis implicações jurídicas, para quem cria e/ou veicula nas redes sociais e similares as pseudoinformações, considerando os danos presumíveis que podem causar à sociedade, por confundir na tomada de decisão da população em fazer ou não, mediante aos argumentos publicizados.

\section{MÉTODO}

Trata-se de um estudo de reflexão que teve como referencial as consequências da aplicação do arcabouço jurídico brasileiro aos casos de Fake News sobre COVID-19. Para tanto, utilizou-se a classificação do banco de dados do Ministério da Saúde, a saber: discursos de autoridades na saúde (40), terapêutica 
(17), medidas de prevenção (9), prognósticos da doença (2) e vacinação $(2)^{4}$.

As fontes são oriundas de outro estud $0^{4}$ pela sua relevância, mas com lacuna deixada no sentido das aplicações pelo ordenamento jurídico. Dessa forma, o mesmo quadro demonstrativo naquele estudo será replicado na íntegra nos resultados dessa investigação.

O procedimento adotado para discussão foi enquadrar os dados encontrados ao ordenamento jurídico vigente como pressupostos das consequências da veiculação das Fake News sobre a COVID-19. Nessa perspectiva, utilizou-se como parâmetros legais os Artigos 5ㅇ, I e 46 (in totum) da Lei no 9.610 de 19 de fevereiro de 1998, a Lei dos Direitos Autorais e a Resolução no 510/2016 do Conselho Nacional de Saúde. Em síntese, a metodologia do estudo se refere ao desdobramento de um artigo já publicado, o que em nada desmerece os resultados, muito pelo contrário, configura a continuação de um estudo anterior.

\section{RESULTADOS}

O Quadro 1 apresenta a classificação das Fake News no banco de dados do Ministério da Saúde em: discursos de autoridades na saúde (40), terapêutica (17), medidas de prevenção (9), prognósticos da doença (2) e vacinação (2) 4 .

Os autores ${ }^{4}$ publicaram exemplos que evidenciam as Fake News, segundo eles a seleção ocorreu de forma aleatória, sendo uma de cada categoria, totalizando cinco. Destas, três foram veiculadas por whatsapp e duas pela internet (quadro 1). Trata-se de pseudoinformações a respeito de precauções de segurança estudos não realizados no meio científico; vitaminas, alimentos, dentre outros, sem evidência científica para a prevenção da COVID-19; prognósticos inconclusivos causados pelo novo coronavírus e; anúncio de vacina contra o vírus circulante ${ }^{4}$.

Em relação a quadro 1, observa-se que as Fakes News que circularam nas redes sociais e similares poderiam ter consequências danosas para um leitor desavisado, caso optassem por alguma conduta inadequada. Percebe-se o uso de argumentos que confundem e semeiam a descredibilidade no campo científico. Em vez de conscientizar sobre o assunto e também o distanciamento social, como medidas de prevenção, causam medo e sentimentos que podem levar ao desequilíbrio emocional, dessa forma, a saúde mental do indivíduo, perante a sociedade, estaria comprometida.

Quadro 1. Quadro de exemplos de Fake News, segundo o Banco de Dados do Ministério da Saúde (BR), Brasil, $2020^{4}$.

\begin{tabular}{|c|c|c|c|}
\hline Categoria & Título da Notícia & $\begin{array}{l}\text { Veículo de } \\
\text { Informação }\end{array}$ & Contra argumentação \\
\hline $\begin{array}{l}\text { Informações relacionadas } \\
\text { aos discursos de } \\
\text { autoridades na saúde }\end{array}$ & $\begin{array}{l}\text { Aplicativo Coronavírus- } \\
\text { SUS, do Governo do } \\
\text { Brasil, é inseguro }\end{array}$ & WhatsApp & $\begin{array}{l}\text { O aplicativo Coronavírus-SUS-COVID-19, foi } \\
\text { desenvolvido pelo Ministério da Saúde, com as } \\
\text { precauções de segurança em sua construção e na } \\
\text { divulgação das informações. }\end{array}$ \\
\hline Terapêutica & $\begin{array}{l}\text { Tomar bebidas quentes } \\
\text { para matar o coronavírus }\end{array}$ & WhatsApp & $\begin{array}{l}\text { A mensagem possui características de Fake News, } \\
\text { pois os dados e informações são vagas, com } \\
\text { erros ortográficos e pede seu compartilhamento. } \\
\text { Ademais, a comunidade científica e a OMS não } \\
\text { reconhecem nenhuma substância ou medicamento } \\
\text { para cura da COVID-19. }\end{array}$ \\
\hline Medida de prevenção & $\begin{array}{l}\text { Beber muita água e fazer } \\
\text { gargarejo com água } \\
\text { morna, sal e vinagre } \\
\text { previne coronavírus }\end{array}$ & WhatsApp & $\begin{array}{l}\text { Até o momento, não há evidência de nenhum } \\
\text { medicamento, substância, vitamina, alimento, } \\
\text { muito menos beber muita água e fazer gargarejo } \\
\text { com estas substâncias para prevenir a infecção } \\
\text { pelo coronavírus (COVID-19). }\end{array}$ \\
\hline Prognósticos da doença & $\begin{array}{l}\text { Pesquisa publicada por } \\
\text { cientistas chineses diz } \\
\text { que coronavírus tornará } \\
\text { a maioria dos pacientes } \\
\text { do sexo masculino infértil }\end{array}$ & Internet & $\begin{array}{l}\text { O artigo citado está em fase de pré-publicação } \\
\text { e não foi revisado pelos pares, portanto tem } \\
\text { pouco valor científico no momento. Esse artigo } \\
\text { traz dados preliminares sobre a possibilidade de } \\
\text { infecção de células do testículo pelo coronavírus } \\
\text { (COVID-19), porém menciona que não existem } \\
\text { dados suficientes para se estabelecer um risco de } \\
\text { esterilidade masculina. }\end{array}$ \\
\hline Vacinação & $\begin{array}{l}\text { China anuncia vacina } \\
\text { para coronavírus }\end{array}$ & Internet & $\begin{array}{l}\text { Não há vacina contra o coronavírus até o } \\
\text { momento, apesar de haver pesquisas em } \\
\text { andamento. }\end{array}$ \\
\hline
\end{tabular}

Fonte: Neto et al. ${ }^{4}$ 


\section{DISCUSSÃO}

\section{A aplicação das técnicas de argumentação na construção das Fake News}

A discussão sobre o que concerne a esse tema será pautada na obra The Intelligence Trap, pois apresenta aos leitores, que algumas pessoas poderão pensar, que se houver alguma verdade na informação, será útil para algum amigo ou seguidor, e caso não seja verdade, acabará sendo algo inofensivo. Assim, o ímpeto será compartilhar, sem perceber o dano que poderá causar ${ }^{9}$.

Esse ato impensado está presente no dia a dia de milhões de pessoas que acessam as redes sociais. Os indivíduos que as leem, seja por medo de mostrarem sua falta de conhecimento sobre determinado assunto e/ou para provarem que possuem conhecimento sobre diversos assuntos, decidem compartilhar, indiscriminadamente, tudo o que visualizam e tem acesso nas redes sociais.

Nessa lógica, a Fake News apresenta determinada linguagem descritiva ou histórias pessoais que parecem realistas. A estratégia é colocar no conteúdo da mensagem, fatos, números, nome de autoridades no campo da saúde, parecer convincente e, assim, convencer o leitor, com base nos argumentos ${ }^{9}$.

A estratégia mencionada é bem articulada dentro de uma estrutura procedente do conceito da teoria da comunicação. Observando a produção das Fake News, é preciso entender a construção de alguns argumentos aplicáveis nas pseudoinformações. O primeiro argumento é de autoridade, que ocorre com o uso de citações de autoridade do campo, bem como autores renomados ou similares como fiadores da veracidade. O segundo argumento origina-se com base no consenso, trazendo as proposições evidentes por si ou universalmente aceitas, para efeitos argumentativos. $\mathrm{O}$ terceiro argumento é baseado em provas concretas, quando são citadas, a saber: cifras, estatísticas, dados históricos, experiência vivida, dentre outras, nessa linha de pensamento. O quarto argumento se constitui com base no raciocínio lógico, o que representa citações de causa e efeito. O quinto e último argumento se refere à competência linguística, quando termos técnicos são aplicados ${ }^{10}$.

As técnicas de argumentação no caso das Fake News direcionam nosso olhar para outro aspecto técnico denominado de AIDA, que significa Atenção, Interesse, Desejo e Ação, tendo por efeito esperado a atitude do consumo. ${ }^{11}$ Isto coaduna com a estratégia de argumentação, que explora os recursos para levar o leitor a crer a verdade, em palavras, nas construções do texto.

Entender a construção das mensagens de Fake News é perceber que são elaboradas de forma aleatória, mas com determinada estrutura, atendendo interesses adversos, sejam no campo social, cultural, político, econômico e dentre tantos outros que visam interesses próprios.

A questão a ser pensada é: quais seriam as consequências jurídicas aos danos causados pelas Fake News ao indivíduo?

\section{As Fake News à luz do ordenamento jurídico brasileiro}

Partindo do pressuposto que as Fake News são consideradas pseudoinformações dos agravos à saúde e, que suas ocorrências interferem no campo social, político e sanitário, confundindo a população, dificultando a tomada de decisões sobre os cuidados relacionados à saúde, principalmente em relação à pandemia da COVID-19, se faz necessário discutir, por meio do arcabouço jurídico brasileiro, a existência legal que poderá ser utilizada no combate das Fake News, sobretudo naquelas relacionadas à COVID-19.

Para iniciar a discussão proposta, é importante esclarecer que as leis brasileiras punem não apenas o autor de uma Fake News, mas também as pessoas que compartilham tais informações indiscriminadamente.

A Fake News veiculada nas mídias sociais pode causar desastres ou perigos inexistentes, ocasionar medo, pânico, dentre outras emoções e sentimentos. Por esses motivos, o agente propagador poderá ser punido com fundamento no artigo 41 do Decreto-Lei no 3.688 de 3 de outubro de 1941, ou seja, na Lei de Contravenções Penais ${ }^{12}$ e será aplicada a pena de prisão simples de 15 dias a 6 meses ou multa. Como exemplo desse ato, cita-se uma fotografia que circulou em redes sociais, onde se via supostos corpos no chão de uma cidade e relacionavam, falsamente, à imagem de corpos de vítimas da COVID 19 na Itália, dentre outros ${ }^{13}$.

Destaca-se também o Decreto-Lei no 2.848 , de 7 de dezembro de 1940, que é o Código Penal brasileiro (CP),${ }^{14}$ o qual apresenta diversas formas de se punir, tanto o autor das Fake News, como aquele que a divulga, como poderá se constatar nos parágrafos subsequentes.

Atualmente, é comum a divulgação de notícias sobre supostos medicamentos e práticas de cuidados para combater a COVID-19 como, por exemplo, uma notícia que apontava a exposição ao sol para evitar a contaminação por COVID-19 ${ }^{15}$. Ocorre que, no caso de se expor a vida ou a saúde das pessoas a perigo direto e iminente, o artigo 132 do $\mathrm{CP}^{14}$ prevê a pena de detenção, de três meses a um ano, se o fato não constituir crime mais grave.

O Artigo 171 do CP, ${ }^{14}$ pune o estelionato, e tem por objetivo proteger o patrimônio das pessoas e prevê punição para aquele que enganar a pessoa de boa-fé, induzindo-a ao erro, a fim de obter vantagem, com a pena de reclusão, de um a cinco anos, e multa. Infelizmente, esse tipo de delito é o que mais ocorre, atualmente, nas redes sociais, quando o agente busca retirar valores monetários da vítima.

A título de exemplo, seguem alguns casos de estelionato praticado pela internet em tempos da COVID-19: o e-mail ou uma página falsa, se fazendo passar por uma pessoa necessitada ou uma empresa idônea, solicitando doações de dinheiro para supostas pessoas ou organizações de ajuda às vítimas da COVID-19.

É notório que um dos pilares para se evitar o aumento dos casos da COVID-19 é o distanciamento social. Assim, aquela pessoa que, mesmo depois de determinações do poder público 
para se isolar sobre o lema "fique em casa", divulga notícias e incita a burla a essa determinação, também, pratica um crime previsto no artigo 268 do $\mathrm{CP}^{14}$ e poderá ser punida com detenção de 1 mês a 1 ano se infringir a determinação do poder público destinada a impedir introdução ou propagação de doença contagiosa.

O exercício ilegal da profissão é classificado como crime previsto no art. 282 do CP. Com a pandemia da COVID-19, tem-se observado diversas notícias e áudios nos meios de comunicação de supostos profissionais da área da saúde, geralmente, em tom alarmante sobre a pandemia ou, até mesmo, receitando algum medicamento, realizando consultas ou prescrevendo medicamentos por meio de redes sociais. Esses casos podem ser enquadrados nesse crime e terão como punição a pena de detenção de 6 meses a 2 anos $^{14}$.

O CP também pune aqueles profissionais da saúde ou não, que divulgam curas ou remédios que, supostamente, seriam infalíveis ao combate e erradicação da COVID-19 sem comprovação científica ou regulação por agência sanitária competente. Trata-se de crime denominado de charlatanismo previsto no artigo 283 do $\mathrm{CP},{ }^{14}$ que prevê pena de detenção de 3 meses a 1 ano e multa.

O Artigo 284 do $\mathrm{CP}^{14}$ se destina a punição da prática do curandeirismo. O Código Penal brasileiro é datado de 1940 e para interpretar melhor o Artigo 284, devemos levá-lo em consideração. Hoje, as práticas adotadas na saúde coletiva e a liberdade religiosa que a sociedade conquistou, iniciou nessa época. Assim, o que poderia ser uma arte ou uma técnica, afirmando o poder de cura, por meio de forças misteriosas, como a ajuda de deuses, espíritos, mortos, entre outros, era algo pretensioso de interpretação desse artigo.

De fato, o argumento que embasava o crime de curandeirismo pretendia proteger a população das falsas crenças e das falácias profissionais, reprimindo os falsários ${ }^{16}$.

Em tempos da COVID-19, o crime do artigo 284 do $\mathrm{CP}^{14}$ é praticado por aquele que se apresenta como suposto curandeiro em redes sociais com o intuito de prescrever, ministrar ou aplicar qualquer substância e realizando diagnósticos sem nenhuma comprovação científica. Para esses casos, a pena é de detenção de 6 meses a 2 anos, além da cobrança de multa.

Constata-se outras duas ações criminosas que ocorrem, atualmente, em nossas redes sociais relacionadas à COVID-19. Para esses casos, observa-se, por exemplo, 70 registros $^{4}$ no banco de dados do Ministério da Saúde. As denúncias efetuadas foram em redes sociais contra profissionais de saúde e gestores de hospitais públicos e privados.

As Fake News são inconformidades que geram indícios de infrações, por meio de denúncias, de qualquer origem, sejam pelos supostos descasos dos profissionais de saúde, dos gestores públicos e privados, das supostas condições de atendimento, supostas faltas de materiais, insumos, dentre outras, sempre na mesma linha de pensamento.

Decerto, precisam ser investigadas, mas quem realiza a denúncia ou a dissemina, indiscriminadamente em redes sociais, deve tomar cuidado, pois pode responder penalmente com base no artigo 339 do $\mathrm{CP}^{14}$, que aponta pena de reclusão de 2 a 8 anos àquele que der causa a instauração de investigação policial, de processo judicial, de investigação administrativa, inquérito civil ou ação de improbidade administrativa contra alguém que o sabe inocente. $\mathrm{O}$ crime do Artigo 339 do $\mathrm{CP}^{14}$ trata da denúncia caluniosa e se configura quando quem a realiza sabe que não é verdadeira. Infelizmente, tal prática ocorre, na maioria das vezes, por inveja, rixa ou tentativa de obtenção de cargo ou posto de trabalho com o afastamento de quem o exerce de forma legítima e reta.

O Artigo 340 do $\mathrm{CP}^{14}$ tipifica a comunicação falsa de crime que pode ser, por exemplo, a informação de que profissionais de saúde não estão realizando seu ofício corretamente ou que hospitais de um determinado município estão recusando atendimento a pacientes com suspeita da COVID-19, é um crime punido com detenção de 1 a 6 meses de prisão ou multa.

É oportuno esclarecer que as Fake News sobre COVID-19 podem ser enquadradas em dois artigos do CP, a saber o 339 e o 340, contudo destaca-se que há diferença entre eles. O artigo 339 do $\mathrm{CP},{ }^{14}$ pune a denúncia caluniosa e, nesse caso, o suposto crime recai contra um indivíduo específico. Já a punição prevista no Artigo 340 do $\mathrm{CP},{ }^{14}$ trata-se de comunicação falsa de crime, quando ocorre contra qualquer um, ou seja, não existe um suposto agente específico.

Por conseguinte, as Fake News são motivos de preocupação, especialmente, no campo da saúde, mormente no domínio da enfermagem. Isso se deve em virtude não só da pandemia, que é considerada uma agravante, mas por disseminar informações inverídicas sobre os cuidados que acometem a população. Logo, ao serem propagadas trazem prejuízos em diversos cenários e, em especial, no cenário da saúde, principalmente em relação aos cuidados, sejam eles domiciliares e/ou institucionais, pois ficam sob risco pelas incertezas ocasionadas, devido às pseudoinformações, o que certamente configura uma violação contra a vida humana, bem como pelos aspectos éticos que elas infringem.

\section{CONSIDERAÇÕES FINAIS}

Ao final deste artigo é possível identificar que a prática de compartilhamento de mensagens, imagens, áudios e/ou vídeos realizadas por diversos indivíduos nas redes sociais, sem a preocupação de verificar se são verídicas, consiste em um ato que pode ser configurado como crime.

Portanto, trata-se de ato criminoso criar e/ou difundir diversas Fake News, em especial, com o intuito de obter a vantagem patrimonial ilícita, o que caracteriza a prática do estelionato e ferir os aspectos éticos. Com a pandemia causada pela COVID-19 essa prática se tornou rotineira, porque muitas pessoas com o intuito de se popularizarem, prejudicam outrem como uma das estratégias políticas ideológica de disseminarem grandes quantidades de informações falsas na internet, situação flagrantemente ilegal frente ao ordenamento jurídico brasileiro. 
Deve-se destacar que as limitações do estudo borram na temática, ainda, pouco explorada em outros estudos, o que torna o percurso de análise e discussão com possíveis fragilidades em virtude das parcas publicações. No entanto, isto também é justificativa que ratifica a sua importância.

Nessa acepção, verifica-se que este estudo traz à tona a problemática dos danos causados pelas Fake News e seus enquadramentos no ordenamento jurídico brasileiro, em especial, na pandemia da COVID-19, como uma das preocupações para enfermagem que visam o cuidado em saúde.

Nessa lógica, enfatizar um tema pouco explorado pelos profissionais da área da saúde, sobretudo pelos enfermeiros é salutar, e desperta para novos estudos. Destarte, contribui para enriquecer as discussões sobre o tema, pois expõe informações que podem, por exemplo, auxiliar na elaboração de políticas públicas, a fim de prevenir, e evitar tais atitudes e demarcar a enfermagem como vigilante no combate as Fakes News.

Além disso, o tema abordado permite esclarecer melhor as pessoas sobre os riscos em fazerem e/ou compartilharem Fake News. Por derradeiro, almeja-se com este artigo que as pessoas obtenham esclarecimento suficiente ao receberem uma notícia, imagem ou informação pela internet, se não tiverem a possibilidade de se certificarem da veracidade ou confirmação de fontes idôneas, não as compartilhem indiscriminadamente, pois podem cometer delitos penais e éticos.

\section{CONTRIBUIÇÕES DOS AUTORES}

Desenho do estudo. Alexandre Magalhães de Mattos Ingrid Zuvanov Kahl Costa. Mercedes Neto. Ricardo de Mattos Russo Rafael. Eloá Carneiro Carvalho. Fernando Porto.

Coleta ou produção dos dados. Alexandre Magalhães de Mattos. Ingrid Zuvanov Kahl Costa. Mercedes Neto. Ricardo de Mattos Russo Rafael. Eloá Carneiro Carvalho. Fernando Porto.

Análise de dados. Alexandre Magalhães de Mattos. Ingrid Zuvanov Kahl Costa. Mercedes Neto. Ricardo de Mattos Russo Rafael. Eloá Carneiro Carvalho. Fernando Porto.

Interpretação dos resultados. Alexandre Magalhães de Mattos. Ingrid Zuvanov Kahl Costa. Mercedes Neto. Ricardo de Mattos Russo Rafael. Eloá Carneiro Carvalho. Fernando Porto.

Redação e revisão crítica do manuscrito. Alexandre Magalhães de Mattos. Ingrid Zuvanov Kahl Costa. Mercedes Neto. Ricardo de Mattos Russo Rafael. Eloá Carneiro Carvalho. Fernando Porto.

Aprovação da versão final do artigo. Alexandre Magalhães de Mattos. Ingrid Zuvanov Kahl Costa. Mercedes Neto. Ricardo de Mattos Russo Rafael. Eloá Carneiro Carvalho. Fernando Porto.

Responsabilidade por todos os aspectos do conteúdo e a integridade do artigo publicado. Alexandre Magalhães de Mattos. Ingrid Zuvanov Kahl Costa. Mercedes Neto. Ricardo de Mattos Russo Rafael. Eloá Carneiro Carvalho. Fernando Porto.

\section{EDITOR ASSOCIADO}

Cristina Rosa Baixinho

\section{REFERÊNCIAS}

1. Ministério da Saúde (BR). Saúde sem Fake News [Internet]. Brasília: Ministério da Saúde; 2018 [citado 2020 maio 22]. Disponível em: https:// www.saude.gov.br/fakenews

2. Neto M, Porto F. O que o passado tem a nos ensinar sobre a Influenza? Rev enferm UERJ. 2019 set;27:e40236. https://doi.org/10.12957/ reuerj.2019.40236.

3. Rafael RMR, Neto M, Carvalho MMB, David HMSL, Acioli S, Faria MGA. Epidemiologia, políticas públicas e COVID-19. Rev enferm UERJ. 2020 abr;28:e49570. https://doi.org/10.12957/reuerj.2020.49570.

4. Neto M, Gomes TO, Porto FR, Rafael RMR, Fonseca MHS, Nascimento J. Fake News no cenário da pandemia de COVID-19. Cogitare enferm 2020;25:e72627. http://dx.doi.org/10.5380/ce.v25i0.72627.

5. Allcott H, Gentzkow M. Social media and Fake News in the 2016 election. J Econ Perspect. 2017;31(2):211-36. http://dx.doi.org/10.1257/ jep.31.2.211.

6. Organização das Nações Unidas para a Educação, a Ciência e a Cultura. Specificities of cyberspace [Internet]. Paris: UNESCO; 2020 [citado 2020 abr 20]. Disponível em: http://www.unesco.org/cybersociety/ cyberspace spec.htm

7. Ferreira IS. Novas fronteiras do direito na era digital. São Paulo: Saraiva; 2002. p. 146-53

8. Ministério da Saúde (BR). Secretaria de Vigilância em Saúde. Boletim Epidemiológico. Especial: doença pelo coronavírus 2019 [Internet] Brasília: Ministério da Saúde; 2020 [citado 2020 abr 20]. Disponíve em: https://www.saude.gov.br/images/pdf/2020/April/06/2020-04-06BE7-Boletim- Especial-do-COE-Atualizacao-da-Avaliacao-de-Risco. pdf

9. Robinson D. Por que pessoas inteligentes caem em mentiras e notícias falsas sobre o coronavírus? [Internet]. BBC News Brasil. 2020 abr 12 [citado 2020 abr 20]. Disponível em: https://www.bbc.com/portuguese/ vert-fut-52239918

10. Fiorin JL, Saviololi FP. Lições e texto: leitura e redação. São Paulo: Ática; 2011.

11. Rosa JA, Cunha TCG. Jornal de empresa - criação, elaboração e administração. São Paulo: STS; 1999.

12. Decreto-Lei no 3.688 de 3 de outubro de 1941 (BR). Lei das Contravenções Penais. Diário Oficial da União [periódico na internet], Brasília (DF). 3 out 1941 [citado 2020 maio 20]. Disponível em: http://www.planalto. gov.br/ccivil_03/decreto-lei/del3688.htm

13. Estado de Minas. Checamos: foto de corpos no chão não é de vítimas de coronavírus na Itália [Internet]. Estado de Minas. 2020 abr 16 [citado 2020 maio 20]. Disponível em: https://www.em.com.br/app/noticia/ internacional/factcheck/2020/04/16/interna_internacional,1139100/ checamos-foto-de-corpos-no-chao-nao-e-vitimas-coronavirus-na-italia shtml

14. Decreto-Lei no 2.848 de 7 de dezembro de 1940 (BR). Código Penal. Diário Oficial da União [periódico na internet], Brasília (DF). 31 dez 1940 [citado 2020 maio 2] Disponível em: http://www.planalto.gov.br/ ccivil_03/decreto-lei/del2848compilado.htm

15. UOL. Tomar sol vira moda na Indonésia após Fake News sobre coronavírus; entenda [Internet]. UOL Viva Bem; 2020 abr 30 [citado 2020 maio 2]. Disponível em: https://www.uol.com.br/vivabem/noticias/ rfi/2020/04/30/tomar-sol-vira-moda-na-indonesia-apos-fake-newssobre-coronavirus-entenda.htm

16. Peixoto ID. Superstição e crime no Brasil. São Paulo: Editora Revista dos Tribunais; 1980 